\title{
Mercado de trabalho sob mediação digital: um estudo de termos em plataformas digitais às ofertas de vagas no setor de arquivos.
}

Laboral Market under digital mediation: a study of terms on digital platforms in job offers in the archival sector

\author{
Taiguara Villela Aldabalde * \\ Kátia Isabelli Melo ** \\ Jean-Rémi Bourguet ${ }^{* * *}$
}

\section{RESUMO}

Objetiva mapear os termos que designam o profissional de arquivo em plataformas digitais e identificar os nichos ao mercado de trabalho. Adota pesquisa documental considerando as ocorrências semânticas de informações laborais relativas às vagas ofertadas, ocupadas e/ou mediadas nas plataformas digitais Indeed, LinkedIn e Catho. Conclui que há 21 designações semânticas distintas em uso para a vaga de emprego deste profissional no mercado e é possível identificar os seguintes nichos representados em plataformas: Documentação Técnica, Sistemas de Informação, Processamento Arquivístico e Gerenciamento de Registros.

Palavras-chave: Mercado de Trabalho; Mediação Digital; Profissional de Arquivo; Plataformas Digitais; Web.

\begin{abstract}
The goal is to map the terms that designate archival professional on digital platforms and identify the niches in the job market. This study adopted the documentary research considering the semantic occurrences of job information related to offered, occupied and/or mediated vacancies on the digital platforms Indeed, Linkedin and Catho. The study concludes that there are actually 21 different semantic variations to represent these professional in the market and identifies the following niches represented on the digital platforms: Technical Documentation, Information Systems, Archival Processing and Records Management.
\end{abstract}

Keywords: Labour Market; Digital Mediation; Archival Professional, Digital Platforms; Web.

\footnotetext{
* Doutor em Ciência da Informação pela Universidade de Brasília (UnB). Professor do Programa de PósGraduação em Ciência da Informação da Universidade Federal do Espírito Santo (Ufes). Endereço: Avenida Fernando Ferrari, 514, Centro de Ciências Jurídicas e Econômicas, Vitória, ES, CEP 29075-053. Telefone: (27) 4009-2794. E-mail: taiguara.aldabalde@ufes.br.

** Doutora em Archivos y Bibliotecas en el Entorno Digital (Universidad Carlos III). Professora do Curso de Arquivologia da Universidade de Brasília. Endereço: Edifício da Biblioteca Central, Entrada Leste, Mezanino, Brasília, DF, CEP: 70.919-970. Telefone: (61) 3107-2635. E-mail: isabelli@unb.br.

*** Doutor em Ciência da Computação (Université de Montpellier). Professor do Curso de Ciência da Computação da Universidade Vila Velha. Endereço: Av. Comissário José Dantas de Melo, 21 - Boa Vista II, Vila Velha -ES, 29102-920. Telefone: (27) 99238-4903. E-mail: jean-remi.bourguet@uvv.br.
} 


\section{INTRODUÇÃO}

140 bilhões de reais: esse é o valor aproximado atual referente ao montante pago pela Microsoft pela aquisição da plataforma Linkedln. Este dado pode ser provocativo para destacar o valor do estudo de objetos concretos inseridos na cadeia de valor do capitalismo informacional. Tais objetos concretos compõe a materialidade da mediação, vide que são parte dos processos informacionais e "objetos aí envolvidos (interfaces, lógica algorítmica, construção de banco de dados, princípios escondidos em documentos técnicos [...] algoritmos, interfaces, dispositivos, [...] redes de comunicação, espaços de uso etc.". (LEMOS, 2020, p.58, grifos dos autores).

Neste fito, considera-se que este estudo contribui para conhecer a materialidade do trabalho relacionado à informação digital. Assim, por um lado a proposta não está fixada em explicar o fenômeno, pois não se trata de um trabalho explicativo, por outro busca-se trazer à nota novos dados sobre objetos digitais (termos de designação do profissional, nuvens de palavras e nichos, por exemplo). Esses objetos são relevantes para conhecer o funcionamento semântico na representação informacional do mercado de trabalho sob a mediação digital'.

Isto posto, o presente estudo pretende descobrir novos dados e oportunizar possíveis reflexões sobre o funcionamento de objetos concretos sobre o atual modo de produção capitalista sob a lógica dos termos patrocinados, que conforme Dantas (2016), obedece uma cadeia de valores de palavras em função da relação entre os leiloeiros, espaços publicitários e os anunciantes.

Assim, objetiva-se mapear os termos que representam o profissional de arquivo em um determinado mercado de trabalho sob mediação em plataformas digitais a fim de identificar as designações deste profissional e os nichos classificados, tendo por base as representações informacionais das vagas ofertadas, ocupadas e mediadas digitalmente no espaço de três plataformas digitais, nomeadamente Indeed, LinkedIn e Catho.

\section{PROCEDIMENTOS METODOLÓGICOS}

Adota-se a pesquisa documental em duas partes distintas e complementares. A primeira trata-se de uma pesquisa bibliográfica em obras consideradas pertinentes para que os novos dados descobertos pelo trabalho possam ser localizados no conhecimento e em relação potencial com as a temáticas transversais e/ou afins ao estudo, pois o mesmo é original e não se acha trabalho similar até o presente momento.

A segunda parte, corresponde à pesquisa arquivística (archival research) em registros nato-digitais mediados nas plataformas digitais Indeed, Linkedln e Catho. As técnicas de coleta de dados utilizadas variaram conforme a plataforma, porque no caso da Indeed, foi possível realizar a captura de dados com um script de Web scraping que coletou os dados referentes às ofertas e arquivou os dossiês de registro no computador.

Este procedimento permitiu a extração de dados para a análise quali-quantitativa. Já na plataforma Linkedln constata-se que há um mecanismo inibidor da API (Application Programming Interface), que coloca os dados fechados para o reuso, assim foi

\footnotetext{
${ }^{1}$ Mais a seguir explicita-se o que é considerado como mercado de trabalho sob a mediação digital
} 
possível apenas uma abordagem qualitativa da metodologia adotada. Em se tratando da Catho, também se optou apenas pela abordagem qualitativa.

A partir da coleta e armazenamento de dados, buscou-se realizar uma análise de ocorrências, entendidas como as representações da informação por meio da semântica. Neste sentido, as nuvens de palavras foram geradas a partir dos 150 tokens mais frequentes desconsiderando as palavras sem sentido ou stopwords, que se relacionavam a cada termo de entrada na plataforma Indeed.

A partir destas nuvens foi possível realizar as alocações destas aos nichos. Já o tratamento de dados da abordagem qualitativa para Linkedln e Catho, foi limitado a definir quais os termos em search engines eram encontrados em uma constante revalidação e atualização das palavras. As coletas ocorreram entre maio e novembro do ano de 2019 no universo delimitado, isto é, refere-se às plataformas de anúncios de mercado laboral, particularmente aquelas vagas relacionadas ao mercado de trabalho do profissional de arquivo.

\section{MERCADO DE TRABALHO SOB MEDIAÇÃO DIGITAL: BREVES APONTAMENTOS INTRODUTÓRIOS AO TEMA.}

A presente seção considera explicitar entendimentos acerca do que é a mediação digital e sua ligação com o mercado de trabalho sem deixar de lado as plataformas digitais. A partir desta explicitação, busca-se possibilitar que o presente trabalho possa ser apropriado e inserido em relação a outras investigações em temas afins com diferentes abordagens.

Ao enunciar que o mercado laboral está sob mediação digital, considera-se relevante introduzir a seguinte ideia: a mediação é um processo institucionalizado pelos meios (inclusive de comunicação), caracterizando-se pela intervenção nos elementos estruturantes de um sistema a fim de determinar a apropriação de objetos tais como entidades não-humanas, vide "trabalho" e "capital" (KEMBER E ZYLINSKA, 2012).

Esta noção é suficiente e necessária para entender a mediação digital como um processo de produção, transmissão e recepção de dados através de meios digitais. Sob esta mediação, o mercado de trabalho entendido aqui como conjunto de contratantes e trabalhadores (oferta e procura de trabalho como mercadoria), achase agenciado pelo meio digital, tanto no anúncio de uma vaga ofertada, quanto na busca por um trabalho.

Deste modo, as plataformas aqui estudadas, diferem-se das plataformas digitais laborais de Van Doorn (2017) e Casilli (2019), pois estas plataformas digitais laborais analisadas por estes autores estão ligadas ao fenômeno do Uber estudado por Van Doorn (2017) e aqui não se confundem com as plataformas de anúncios de vagas laborais. As primeiras são lugares de automatização de processos de trabalho e as segundas são espaços de anúncios de vagas laborais no campo das mídias sociais.

Mercadologicamente ${ }^{2}$ o tipo de plataformas digitais aqui estudado media digitalmente as demandas financiadas por empresas e agência de recursos humanos.

\footnotetext{
2 Considera-se que: "a mercadologia estuda a demanda e as maneiras de influenciá-la" (SANDRONI, 1994, p.216).
} 
Portanto, conceitualmente as plataformas a seguir estão próximas das chamadas "plataformas de disseminação"3 abordadas em Lemos (2020).

A partir deste entendimento, busca-se conhecer os termos que designam o profissional de arquivo nestas plataformas e identificar os nichos do mercado de trabalho representados na web admitindo que tais objetos de estudo se acham sob um regime de mediação próprio do capitalismo atual. Em outras palavras estão sob uma mediação que obedece a um determinado modo de produção delimitado a seguir: "[...] modo informacional de desenvolvimento, a fonte da produtividade achase na [...] geração de conhecimento, de processamento da informação [...]" (CASTELLS, 1999, p.35).

Portanto, o presente trabalho se insere não apenas no campo da mediação correspondente a área da Ciência da Informação, mas também como contributo para conhecer a materialidade no âmbito do funcionamento da oferta e da procura de vagas em plataformas digitais. A abordagem é original aos objetos digitais (uso de termos, a semântica).

Assim, insere-se no campo das materialidades localizado em Lemos (2020), particularmente os aspectos do funcionamento semântico do mercado de trabalho, os termos usados em ofertas e procura por trabalho no meio digital ao profissional de arquivo, com base nos objetos das plataformas digitais.

Em se tratando da mediação digital como campo do saber, cabe destacar que essa emerge a partir das Ciências da Informação e Comunicação. Isso ocorreu a partir da preocupação com a acessibilidade e a apropriação de informações na esfera digital. Esta mediação está ligada não apenas aos aspectos que podem facilitar o acesso por meio de interfaces, como também ao aprimoramento de todos os esquemas entre os atores e ferramentas (DESCHAMPS, 2019).

Portanto, a mediação digital requer dispositivos tecnológicos para mediar a relação entre os usuários e os usos informacionais, incluindo a navegabilidade, a integração, as necessidades informacionais coletivas, os objetivos pessoais dos usuários, e as formas com que as informações podem ser apropriadas (DESCHAMPS, 2019).

No caso em tela, estes dispositivos tecnológicos são criados, segundo Fuchs e Sandoval (2014), por diversas forças produtivas e estão sob o modo capitalista de produzir e usar a tecnologia digital. Para esses autores há uma categoria de trabalho, o trabalho digital, que envolve, dentre outras coisas, a criação de produtos e informações necessários para o uso desta tecnologia.

Considerando que as plataformas digitais de anúncio de vagas laborais são também produtos da tecnologia digital e são alimentadas por trabalhadores, cabe sublinhar que há uma gama de trabalhadores que compõe a cadeia produtiva digital. Essa abarca aqueles que labutam na produção de peças de computador (hardware) e quaisquer outros componentes associados. Por exemplo: os minerais da placa mãe dos computadores, software e conteúdos informacionais (FUCHS e SANDOVAL, 2014).

Tais anúncios e buscas por uma vaga na web não são meramente espontâneos, mas decorrentes de uma coerção violenta e institucionalizada. Segundo Fuchs e Sandoval (2014), os mercados compõem a violência estrutural em uma sociedade e isso é

\footnotetext{
${ }^{3}$ As plataformas aqui estudadas ocupam o espaço antes reservados aos meios de comunicação nãodigitais (jornais e revistas impressos, por exemplo).
} 
evidente quando os autores tratam dos mercados (de modo geral) como modos de coerção.

Portanto, o movimento do trabalho nas plataformas digitais é estabelecido nas relações coercivas entre a classe dos proprietários e a classe dos não-proprietários, de modo que os não-proprietários são compelidos a entregar aquilo que produzem para ser apropriado pela classe dos proprietários (FUCHS e SANDOVAL, 2014). Podese observar como resultado de uma coerção movimentos como: o anúncio de habilidades pessoais nas plataformas digitais e as atividades de recrutadores de empresas, ofertando vagas com competências definidas segundo os interesses dos proprietários ou dirigentes das propriedades.

Neste caso, tal mediação ocorre em uma diversidade de plataformas digitais que espelham a integração do mercado de exploração de mão de obra sendo as próprias plataformas um produto do trabalho digital. Considera-se assim que, como parece ocorrer em outros mercados, tais como o mercado financeiro, o mercado laboral tem operado por meio de plataformas de diversos modelos.

Deste modo, há plataformas que funcionam como as redes sociais, vide o Linkedln, por exemplo, estando abertas para dispositivos de recrutamento e seleção de forma mais dinâmica e pessoal, ao passo que outras correspondem a um classificado de empregos endereçado aos que buscam contratar ou serem contratados, tais como Indeed e Catho.

Vale lembrar que há um arranjo de forças produtivas que culminam nestas plataformas de vagas de maneira que dentre as variáveis lógicas nesta cadeia produtiva acham-se as seguintes: a força produtiva dos trabalhadores da informação digital, as classes proprietárias, as relações de propriedade, as tecnologias digitais, os objetos na cadeia produtiva, os produtos, os modos de distribuição e as formas de consumo. (FUCHS e SANDOVAL, 2014).

Portanto, entender as práticas do mercado de trabalho sob a mediação digital implica em conhecer o uso da linguagem dos agentes desta mediação operada por meio de plataformas. Essas correspondem a um modelo de negócios no qual Indeed, LinkedIn e Catho correspondem aos leiloeiros e as empresas demandantes de trabalho são os anunciantes voltado aos usuários/públicos em espaços digitais publicitários (DANTAS, 2016).

Deste modo, cabe apontar que no ramo de anúncios e busca de vagas há variáveis envolvidas nestas demandas ao mercado de termos ou palavras-chave (DANTAS, 2016). Neste sentido, é possível estabelecer que dentre as variáveis há aquelas que impactam ou determinam os termos para o profissional de arquivo, notadamente uma: a cultura institucional.

Esta cultura diz respeito não apenas aos valores corporativos e a filosofia da empresa, mas também espelha a relação com os fazeres/saberes, e, isso inclui as práticas que se realizam por meio dos registros como processos administrativos que dependem de documentos, informações e de conhecimento especializado.

Cabe salientar que, uma vez que este estudo é original e não acha-se similar, se encontra em um trajeto particular pelo seu contexto, pois trata-se de um desdobramento das atividades iniciais de pesquisa observacional ${ }^{4}$ e no âmbito do

\footnotetext{
4 Desenvolve-se no Laboratório de Estudos Aplicados em Infoprodutos um infoproduto que dispare aos
} interessados todas as vagas de interesse ofertadas pela web em tempo virtual, coletando-as, 
projeto denominado "Estudos Aplicados e Interdisciplinares em Ciência da Informação".

Nota-se que anteriormente à popularização da Internet, as associações profissionais de arquivistas publicavam as ofertas tanto de estágio curricular quanto de vagas disponíveis e isso ainda ocorre nos Estados Unidos via web. Neste contexto, emerge uma nova forma de divulgação e gestão de oportunidades, isto é, por via de plataformas digitais de anúncios de vagas.

Há transformações que foram paulatinamente introduzidas e com estas novas habilidades e competências, inclusive aquelas pertinentes ao mundo do trabalho da informação digital, foram requeridas passando a fazer parte dos requisitos para a seleção e a investidura no cargo de arquivista (o profissional de arquivo). Com isso, a nomenclatura para o cargo adquire, também, novas terminologias em cumprimento às tendências de mercado representadas no ambiente digital conforme se tratará a seguir.

\section{MAPEANDO TERMOS E NICHOS AO PROFISSIONAL DE ARQUIVO A PARTIR DE REPRESENTAÇÕES EM PLATAFORMAS DIGITAIS.}

O diálogo do mercado de trabalho com perfil do trabalhador de arquivo foi analisado na obra de Souza (2011), como resultado de uma pesquisa de doutorado, na Universidad Carlos III de Madrid. Na ocasião, as ofertas para o ingresso nos espaços de trabalho decorriam, fundamentalmente, dos certames promovidos pelas instituições públicas.

A representação do arquivista nessas instituições foi mensurada em $57 \%$ e se contrapunha às demandas da iniciativa privada, com 39\%. Com menor expressão as vagas nos demais espaços indicava $4 \%$. Arquivista era a designação para o cargo, predominantemente.

Considerando que práticas e representações compõe a cultura institucional, uma empresa pode cultivar práticas arquivísticas mais ou menos valorizadas, organizadas, respeitosas em relação às leis, transparentes, funcionais e, assim, há diversas possibilidades de qualidades de práticas que impactam as demandas do mercado laboral.

Em decorrências destas variações, a percepção do capital informacional nos documentos de arquivo, o potencial de exploração da memória institucional para fins de marketing ou comunicação, o apreço pela segurança jurídica em um conjunto de provas no ambiente de negócios, o respeito aos marcos regulatórios, as boas práticas de governança e as qualidades pertinentes à documentação, dependem da cultura institucional.

É possível afirmar que há ainda uma cultura arquivística, essa pode estar presente nas empresas ainda que de forma mínima, diluída no poder político-diretivo de gerências técnicas e/ou dos tomadores de decisão.

Neste contexto, esta cultura corresponde a um conjunto básico de práticas com e a partir dos documentos de arquivo, de forma que há significado funcional no arquivo que agrega valor à atividade empresarial, dentre outras possibilidades, pela

processando-as, realizando o reuso destes dados para o benefício de distribuição para os finalistas e egressos do curso de Arquivologia 
manutenção ou implementação de uma governança da informação institucionalizada em normas como a ISO 15489-1:2018.

A seguir, levou-se em consideração os termos ou palavras como as representações semânticas geradas a partir de informações, sendo também entendidas como bens simbólicos comercializados na rede (DANTAS, 2016).

Não é sem motivo, que os nichos aparecem separados no capitalismo informacional, pois Castells (1999) realiza o seguinte diagnóstico dos efeitos deste capitalismo para com o mercado de trabalho: trata-se de uma perestroyka capitalista, uma ruptura com o mercado de trabalho tradicional e a criação do chamado "trabalho complementar".

Neste encaminhamento há mais do que a descentralização para o home-office online, porque ocorre a redução das jornadas, a alta fragmentação do trabalho, a quebra dos espaços-tempos de realização do trabalho, o aumento do desemprego, a desregulamentação/desconstrução do contrato social, a corrosão da proteção das normas em escala mundial, e a flexibilização unilateral para atender aos interesses financeiros do modelo informacional conectado via web.

Uma evidência destas rupturas são os próprios nichos ou divisões de um trabalho especializado, visto que está em vigor no capitalismo informacional contratar apenas para realização de tarefas imediatas como digitalizar um arquivo. É notável que o contrato temporário necessita pela natureza dos arquivos, de um complemento com um outro trabalho ou a manutenção do que foi trabalhado, pois o setor de arquivo possui uma demanda contínua.

Assim, um profissional de arquivo que trabalha sob contrato permanente pode aplicar sua expertise em diversos nichos de atuação, ao passo que aquele terceirizado parece estar em uma condição precária resultante da precarização dos contratos como uma das consequências do capitalismo informacional (CASTELLS, 1999).

Considerando os dados coletados na plataforma Indeed, os termos foram agrupados por nuvens de palavras representativas dos nichos. Dentre esses, aquele que pode ser considerado como um nicho primordial, ou seja, antes da separação entre a Arquivologia e a Biblioteconomia, e do surgimento da Ciência da Informação, corresponde ao nicho denominado "Documentação Técnica" coincidindo com o termo em inglês "technical documentation", inicialmente derivado dos documentos produzidos das atividades técnicas das indústrias e/ou das ciências (CACALY, Serge; Le COADIC, 2007). Sendo assim o nicho pode ser representado (Figura 1) por uma nuvem de palavras.

$\mathrm{Na}$ figura abaixo os termos "documento", “documentação", "conhecimento", "requisitos", "qualidade", "análise"5, "conhecimento" e "processos", podem identificar a localização do nicho no mercado de trabalho. É mister salientar que a dita "Documentação Técnica" (representada na Figura 1) não é um fim em si mesmo, mas um meio ou instrumento para alcançar a atividade-fim de alguma empresa com uso de ciência ou conhecimento técnico buscando amparar uma atividade de produção ou prestação de serviço em bases materiais que servem como recursos agregadores de valor (MEAD, 1998).

\footnotetext{
${ }^{5}$ Em Lemos (2020) acha-se a análise de documentos (e não da informação) como uma das atividades elencadas no trabalho de pesquisa. $O$ autor cita as seguintes espécies: a patente, o contrato e o termo de uso. Essas espécies compõe a documentação técnica sendo o pesquisador um dos clientes potenciais do profissional de arquivo.
} 


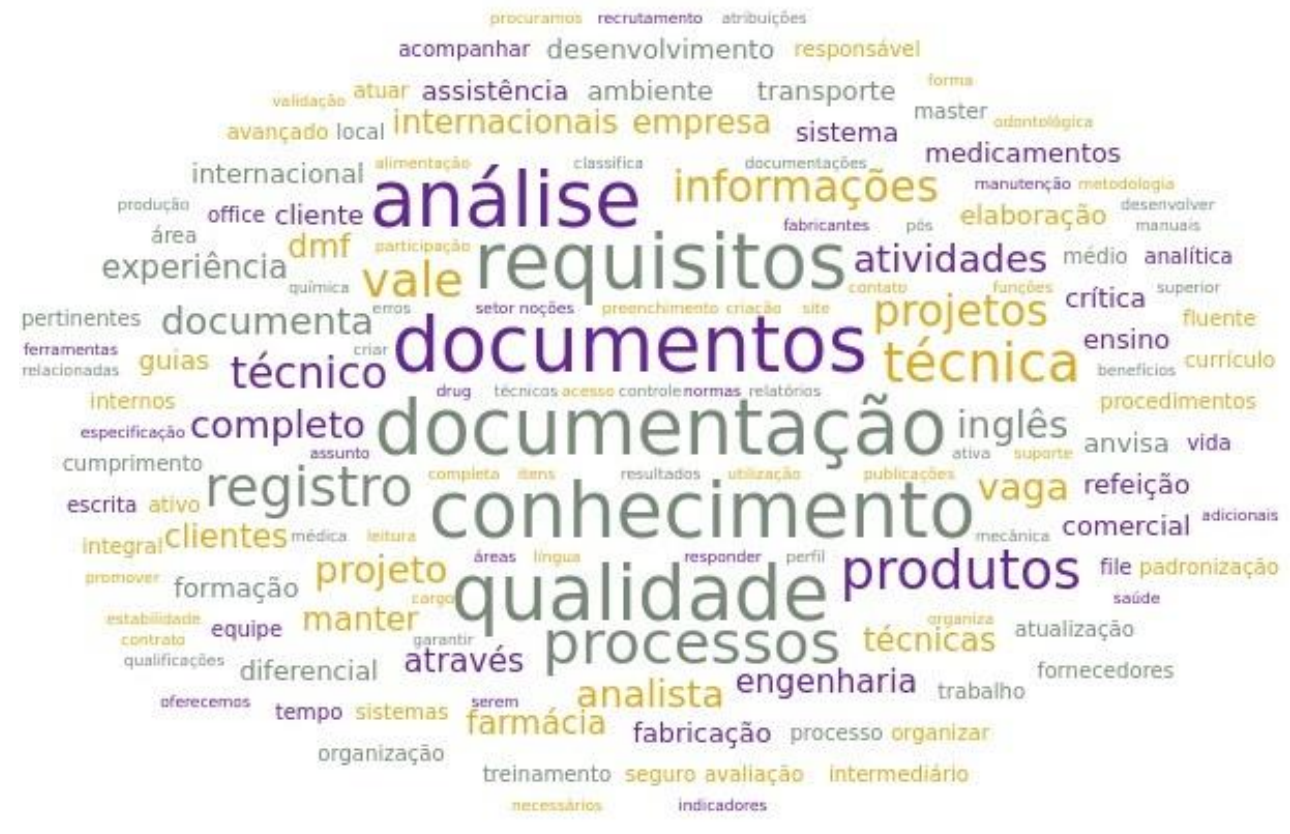

Fonte: Elaborado pelos autores (2019).

Dentre as demandas concernentes a mais-valia qualificada deste nicho está por exemplo, a preocupação com o controle de qualidade, as especificações técnicas, o emprego de conhecimento registrado a ser rigorosamente documentado, a verificação da validade de um software para uma empresa especializada, a manutenção do valor legal efetivo de um documento para uma indústria (MEAD, 1998).

Para além deste valor contingente, o documento de arquivo é resultado da ação de forças produtivas que compõe um sistema de produção criando valor de uso. Esse é aqui considerado como resultante da dialética sujeito-objeto proposta em Fuchs e Sandoval (2014) a partir da qual a cadeia de valor do arquivo instaura as suas possibilidades de valor com valor de uso. Deste modo, o documento arquivístico pode ser identificado no processo de produção econômica com duplo papel: servir de objeto desta produção e de instrumento de trabalho para operacionalizá-la.

A reboque da lógica do capitalismo informacional, este campo é decorrente da aplicação de um conhecimento técnico em uma atividade econômica e sua respectiva documentação. Nesta direção, as diversas atividades científicas ou técnicas contidas no nicho refletem economias locais e regionais de maneira que os territórios com a presença de mineração de petróleo estão suscetíveis a produzir documentação técnica pertinentes a engenharia de petróleo, dentre outros campos de conhecimento aplicado.

Sendo deste jeito, estima-se que é possível considerar, que dentre as variáveis a determinar o nível de desenvolvimento de um país, ou uma região, encontra-se a maturidade deste nicho de mercado. Isso significa que em regiões em vias de desenvolvimento, ou não industrializadas, haverá poucas demandas para os arquivos especializados (ou documentação técnica) em relação as áreas mais industrializadas. 
Por isso, nas plataformas digitais encontram-se oportunidades que correspondem as realidades microeconômicas e locais. No caso do Estado do Espírito Santo, por exemplo, encontra-se por via do LinkedIn, bacharéis em Arquivologia pela Ufes ocupando o cargo de controladores de documentos (document controllers), com ligação à infraestrutura de portos. Essa por sua vez, pode ser associada à exportação local do minério de ferro, siderurgia, aparelhamento de pedras, rochas ornamentais, biocombustíveis, dentre outros. Já no Estado do Rio de Janeiro encontram-se document controllers no setor de Petróleo e Gás possivelmente porque está fixada na capital a sede da Petrobrás, a maior empresa neste setor no país.

Com isto, é possível inferir que o mercado de trabalho sob a mediação digital, ainda que esteja virtualizado, não deixa de refletir a tendência daquilo que é realizado no campo de demandas condicionadas ao desenvolvimento (ou subdesenvolvimento) peculiar de uma região metropolitana, país ou estado. Neste sentido, Fuchs e Sandoval (2014) apontam que o mercado está diretamente ligado à economia capitalista, incluem-no como uma estrutura institucionalizada pertencente ao modo coercitivo formado nas relações da produção e da propriedade com os trabalhadores.

Portanto, a adoção das tecnologias da informação como a instrumentalização dos recursos humanos no capitalismo informacional não tende a significar a sofisticação das gerências de recursos humanos, mas a difusão digital ou conexão em rede das demandas por exploração de mão de obra das unidades da microeconomia local mais ou menos conscientes do papel estratégico da informação.

É possível estimar que, no Brasil, este nicho está ligado as áreas do conhecimento aplicado e consolidado dos arquivos especializados (PAES, 1997), isto é, aos seguintes arquivos: de engenharia, policiais, militares, laboratoriais, de cientistas, de jornais, de escolas, de escritórios de advocacia, de comércio exterior, de administradores de contratos, de criminalística, universitários, contábeis, de inspetorias, paralegais, de mediadores extrajudiciais, de projetos, legislativos, de arquitetura, de monitores de qualidade, de cirurgiões, do judiciário, dentre outros.

Neste raio de alcance encontram-se os documentos arquivísticos como bases materiais indispensáveis para a prova, a informação e a referência técnica, que por vezes é incontornável ao processo de certificação, auditoria ou outro tipo de controle interno ou externo sobre a atividade finalística. Em resumo, as firmas privadas necessitam de manter sua documentação técnica para atender os clientes e/ou executar adequadamente um planejamento em um campo específico de atuação passível de ser regulado.

Já em uma perspectiva complementar às tecnologias da informação, é possível encontrar arquivistas ocupando cargos de analista de informação, analista de gestão e segurança da informação, por exemplo no Linkedln. Existe, deste modo, um outro nicho de mercado que resulta da convergência natural entre os sistemas de informação e as informações de arquivos/information from archives (COOK, 1986). Este nicho pode ser designado pelo termo "Sistemas de Informação" em consonância com o entendimento de Gibbons (2017) sobre estes sistemas que podem ser representados, pelos dados coletados (Figura 2).

$\mathrm{Na}$ figura abaixo (Figura 2) os termos "sistemas", "dados", "usabilidade", "informações", "conhecimento", "arquitetura", "informacional” e "comunicação" estão dentre os termos prevalentes e são representativos deste nicho. Dentre as demandas deste nicho nota-se a digitalização e a transformação digital de atividades fins e meio. Sendo assim, conforme indicam Fuchs e Sandoval (2014), é possível considerar que o trabalho é tratado como uma coisa (um produto digital, ou algo 
resultante de um trabalho em um produto digital, por exemplo). Este tipo de trabalho parece, ao menos em alguma medida, ilustrar a objetificação do trabalho em produto segundo estes mesmos autores.

Tendo em vista que os chamados "sistemas de informação" são produzidos por trabalhadores da informação digital em um contexto que o trabalho é objetificado, a seguir é possível observar a rede de termos que representa o referido nicho sem perder de vista que o termo "sistemas" pode estar relacionado ao desenvolvimento de produtos (novos softwares e designs da informação, por exemplo):

\section{Figura 2 - Representação digital semântica do nicho Sistemas de Informação:}

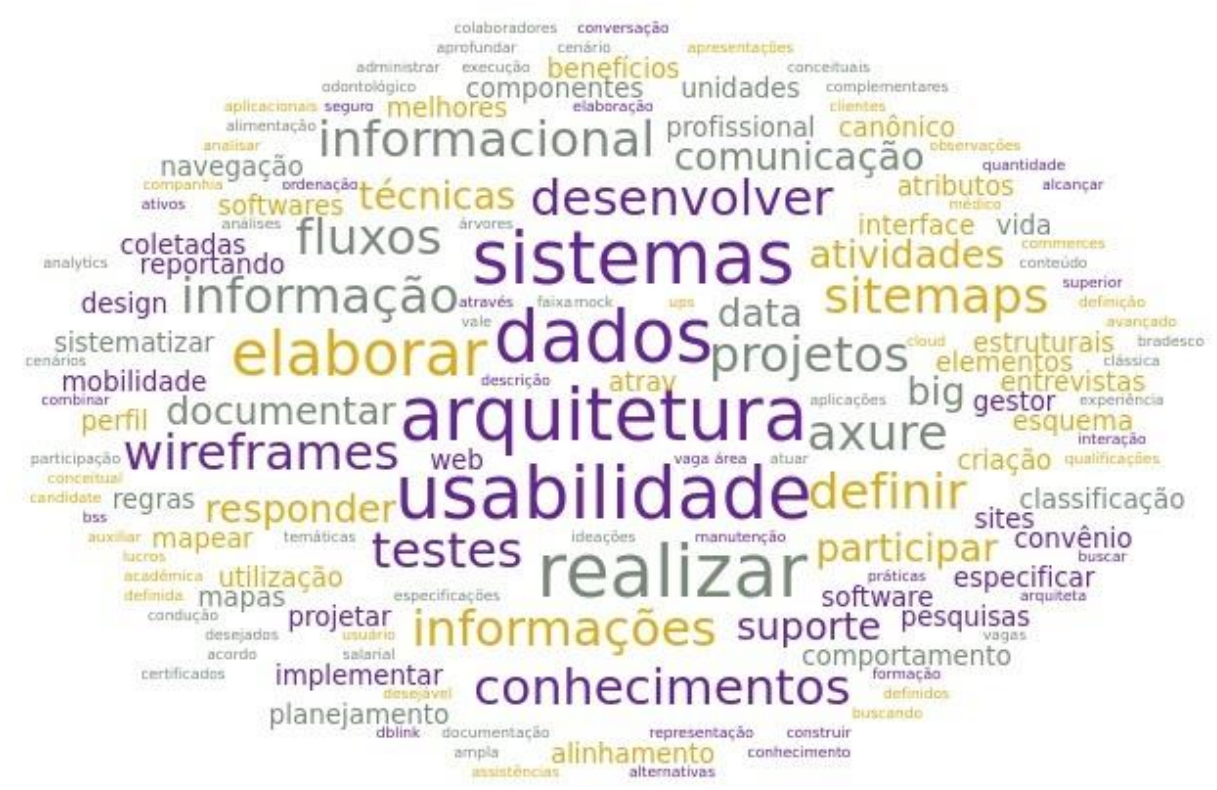

Fonte: Elaborado pelos autores (2019).

Vale lembrar que a força de trabalho demandada é, muitas vezes, direcionada para um período após a realização de uma digitalização sem planejamento ou tecnicamente inconsistente, ou seja, destituída do acompanhamento do profissional de arquivo com expertise na reprografia digital (digitalização). Deste modo, o mercado visa atender os usuários que não conseguem usufruir das cópias digitalizadas dificilmente usáveis e/ou disponíveis.

É considerável que há uma quebra no continuum informacional, sendo isto típico do capitalismo contemporâneo que tem sido fragmentador (CASTELLS, 1999), pois no caso dos arquivos, este continuum inicia-se em uma ação comunicativa (communicative action), passando por um sistema (system) e, sendo enviado a outro sistema no domínio organizacional (org. Domain). Por fim, essa informação multidimensional encaminha-se para um framework social e pode ser pluralizada em sistemas inter-organizacionais de nível global. Deste modo, o continuum informacional de dimensões no espaço-tempo trata-se de um modelo ligado ao fenômeno da informação orgânica registrada a ser trabalhada para facilitar o seu uso plural (GIBBONS, 2017). 
Cabe pontuar que o nicho dos Sistemas de Informação é composto por entidades lógicas e físicas que podem ser representadas a partir de metadados possibilitando a troca ou a mediação das informações. Isto posto, o enfoque do profissional de arquivo nestes sistemas pode ser a acessibilidade e usabilidade das informações processadas em sistemas de microcomputadores projetados para atender necessidades político-diretivas de uma atividade econômica.

Neste sentido, os sistemas de informação geram uma série de relatórios, ou seja, documentos informativos que podem ser melhorados do ponto de vista de sua arquitetura informacional. Assim o profissional de arquivo neste nicho, deve dominar uma linguagem de programação, ferramentas ou softwares para prototipagem de projetos visuais na web, design de interfaces de usuário, mapas conceituais, gestão de banco de dados, e, técnicas de ciência de dados. Neste seguimento, o profissional de arquivo pode compor uma parte dos trabalhadores digitais elencados por Fuchs e Sandoval (2014), pois, dentre as atividades arquivísticas acham-se a criação, a atualização, a manutenção e o gerenciamento de bancos de dados associados aos documentos arquivísticos digitais.

Somado a isto, parece desejável o conhecimento sobre a publicação ou publicização de parte das informações geradas, pois uma vez tratados, os arquivos devem ser armazenados em condições determinadas para a sua preservação e custódia. Entretanto, a custódia no nicho designado "Sistemas de Informação" não significa guarda isolada, mas uso com base em valores, o documento de valor estético, por exemplo, que é usado a fim de produzir um efeito comunicacional (HERSCOVICl, 1995) para a difusão, o compartilhamento, a mediação digital em redes sociais, a produção de vídeo e comunicação em canais de empresas como YouTube, dentre outras possibilidades de uso.

Aliás, em termos práticos e teóricos este nicho possui convergências com a chamada "mediação digital" das Ciências da Informação e Comunicação (DESCHAMPS, 2019). Ocorre que tal mediação corresponde a uma integração entre as plataformas e os agentes da economia da comunicação, da informação e da cultura com os usuários e os produtores de informação sem que estejam estes dois últimos estejam conscientes de suas responsabilidades.

Neste sentido, Duranti (2015) aponta que as informações digitais têm sido prodused, ou seja, ao mesmo tempo "produced" e "used". Em um encaminhamento para caracterizar isto, a autora destaca que as empresas têm se comportado de forma indeterminada sobre a produtividade destas informações no que tange ao longo prazo, desatentando ao crescimento desta produção, da necessidade de cumprir o compliance e a accountability, não só ao presente como ao futuro.

Assim a autora pontua que a atuação do profissional de arquivo refere-se ao suporte dado a estas empresas cujas responsabilidades podem ser instadas por autoridades reguladoras mediante a verificação dos arquivos. Em termos de uma real inserção do profissional de arquivo, este nicho pode ser considerado novo e ainda pode ser mais desenvolvido, principalmente por iniciativas robustas dos agentes dos setores da informação e das tecnologias informáticas que se proponham a resolver problemas interdisciplinares. É possível acrescentar que o profissional de arquivo desempenha um papel fundamental para o capitalismo informacional, pois operam a matéria-prima para além do senso comum dos produsers (DURANTI, 2015).

É notável que, de forma similar, os usuários sejam incluídos pelos Fuchs e Sandoval (2014) no mercado de trabalho, entendidos como prosumers (usuários produtivos), isto é, estão no rol dos trabalhadores relevantes que são criadores/produtores de 
conteúdo e ao mesmo consumidores das informações digitais produzidas. Nesta direção o próprio conceito de produção é entendido pelos autores como um objeto do mundo do trabalho (ou laboral), sendo a tecnologia (digital) uma ferramenta que viabiliza a transformação de um objeto (informação digital, por exemplo) em um produto (FUCHS e SANDOVAL, 2014).

Dadas tais circunstâncias de produção, o mercado de trabalho digitalmente mediado é uma consequência do capitalismo informacional. Essa assertiva apoia-se no modo de funcionamento do capital como algo dependentemente da ampliação das potencialidades de trabalho e de adições de novos valores e usos agregado aos produtos trabalhados no passado, para que sejam novos produtos. Isso inclui as máquinas (microcomputadores, por exemplo) e objetos (plataformas digitais, redes semânticas, termos, nuvens de tags, dentre outros), que são instrumentos de controle tendendo para a redundância e ao mesmo tempo abertos para a originalidade (DANTAS, 2006).

Já em um seguimento mais tradicional, mas nem por isso menos demandado, é possível localizar o nicho designado pelo termo "Processamento Arquivístico" sendo esse compatível com o entendimento de Yakel (2003), pois tradicionalmente Archival Processing está ligado com a descrição, ou seja, a representação arquivística. Este nicho é o campo de aplicação da zona do conhecimento dito "Identificação", ou seja, as empresam carecem de profissionais que sejam capazes de identificar quais tipos, gêneros, formatos, formas, espécies, ou qualquer outra variável do material de arquivo, para que os dados sejam selecionados a fim de compor a base, ou, para organizar o arquivo. No campo da Ciência da Informação, corresponde ao que Buckland (2017) denominou pelo termo "naming".

Apesar de tradicional, este nicho permanece distante do senso comum, pois com a popularização dos microcomputadores a partir dos anos 1990 ocorreu a difusão da ideia de que todos os arquivos indiscriminadamente seriam transferidos para o processamento automatizado. Contudo, o processamento computacional não obliterou o domínio do processamento cibernético, pois esse não é exclusividade da informática (CHIAVENATO, 1987). Dado isto, o que pode se verificar é que os processamentos são não-excludentes e não raramente estão interligados na sua desorganização ou organização. A Figura 3 representa tal nicho: 
Figura 3 - Representação digital semântica do nicho Processamento Arquivístico.

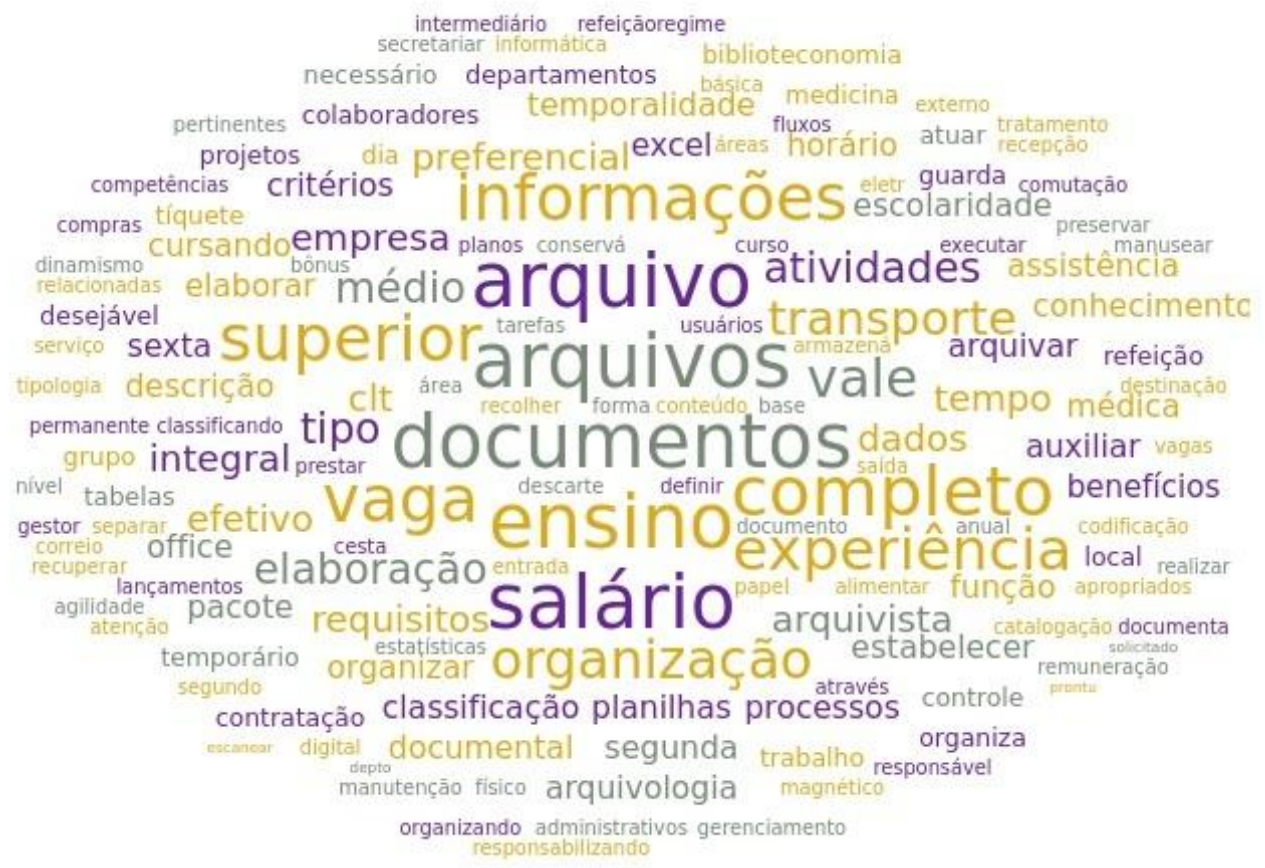

Fonte: Elaborado pelos autores (2019).

$\mathrm{Na}$ figura acima os termos "Arquivo", "arquivar", "organização", "arquivos", "documentos", “classificação", "guarda”, "permanente”, "arquivista”, "organização", "arquivologia", "descrição" e "informações" corresponde aos termos representativos do nicho Processamento Arquivístico. Nota-se também a presença de alguns termos menos centrais e menos prevalentes, porém não menos significantes para demarcação do nicho tais como: "controle", "arquivar", “descarte”, “codificação”, “tabelas”, “destinação”, “tipologia”, “planilhas”, “papel”, "temporalidade" e "intermediário".

É digno de nota a presença do termo "Excel” na Figura 3, porque o uso deste software da Microsoft tem atendido os requisitos mínimos para controle de descritores e tem sido usado para o processamento arquivístico. Nesta direção, o domínio de ontologias e o controle de vocabulário é relevante para definir, com precisão, os metadados requisitados e as respostas semânticas obtidas.

Ademais é notável a presença diminuta dos termos "biblioteconomia" e "catalogação". Todos estes termos são compatíveis com a necessidade do mercado e com a lógica capitalista ou lógica de mercado atual, cuja preocupação é solucionada de forma não mediata ou imediatamente a um determinado problema sem atenção para a regulamentação. Dentre os problemas está, por exemplo, uma penalização ou grande montante de prejuízo em um processo na Justiça devido a incapacidade de se provar algo que sirva de defesa, e cuja raiz, são os arquivos desorganizados.

À vista disso, cabe entender que as necessidades informacionais dos que buscam, ou ofertam uma colocação no mercado, refletem os processos cibernéticos, sobretudo

6 Com base na pesquisa na Plataforma Linkedln, sabe-se que o Excel é adotado também pelos controladores de documentos, ou seja, está presente em outros nichos. 
no contexto dos processos de controle no âmbito administrativo (CHIAVENATO, 1987). E, assim, uma vez que o processo arquivístico é também jurídicoadministrativo, consequentemente há demanda ao processamento arquivístico.

Neste nicho, ocorre aplicação de força de trabalho ao que pode ser chamado por "Classificação". Essa também tem sido comumente associada a descrição, principalmente ás técnicas de indexação e catalogação com raízes na área de documentação/biblioteconomia/ciência da informação, porém o inventariamento é demandável. Neste caso, é relevante aos que operam as informações do mercado de trabalho, principalmente os recrutadores virtuais, considerar que as habilidades exigidas devem confluir para a aplicação de descritores aos documentos para finalidades específicas de cada empresa.

Cabe salientar exemplos de metadados incontornáveis aos arquivos são: a data crônica, a data tópica, o estágio de transmissão do original ou cópia, a ação geradora do documento imbricada no tipo documental, as delimitações do suporte, os números de páginas, a presença de sinais de validação, o estado de preservação, a história arquivística ou história de custódia legal, dentre outros.

Destaca-se que o nicho mapeado a seguir, o chamado "Gerenciamento de Registros", corresponde ao nicho consolidando globalmente pelo termo inglês Records Management, sendo o termo originador de Records Management Software (Gerenciamento Eletrônico de Documentos). Esse por sua vez, para a manutenção da qualidade do gerenciamento, deve atender aos requisitos de um sistema informatizado de gestão arquivística de documentos.

Nota-se na figura abaixo (Figura 4), que os termos "conhecimento", "atividades", "controle", "registros", "gestão", "processos", "procedimentos", “documentos", "relatórios", "qualidade”, "administração", "requisitos" e "acompanhamento" aparecem com maior ou menor peso, e são representativos deste nicho.

Figura 4 - Representação digital semântica do nicho Gerenciamento de Registros.

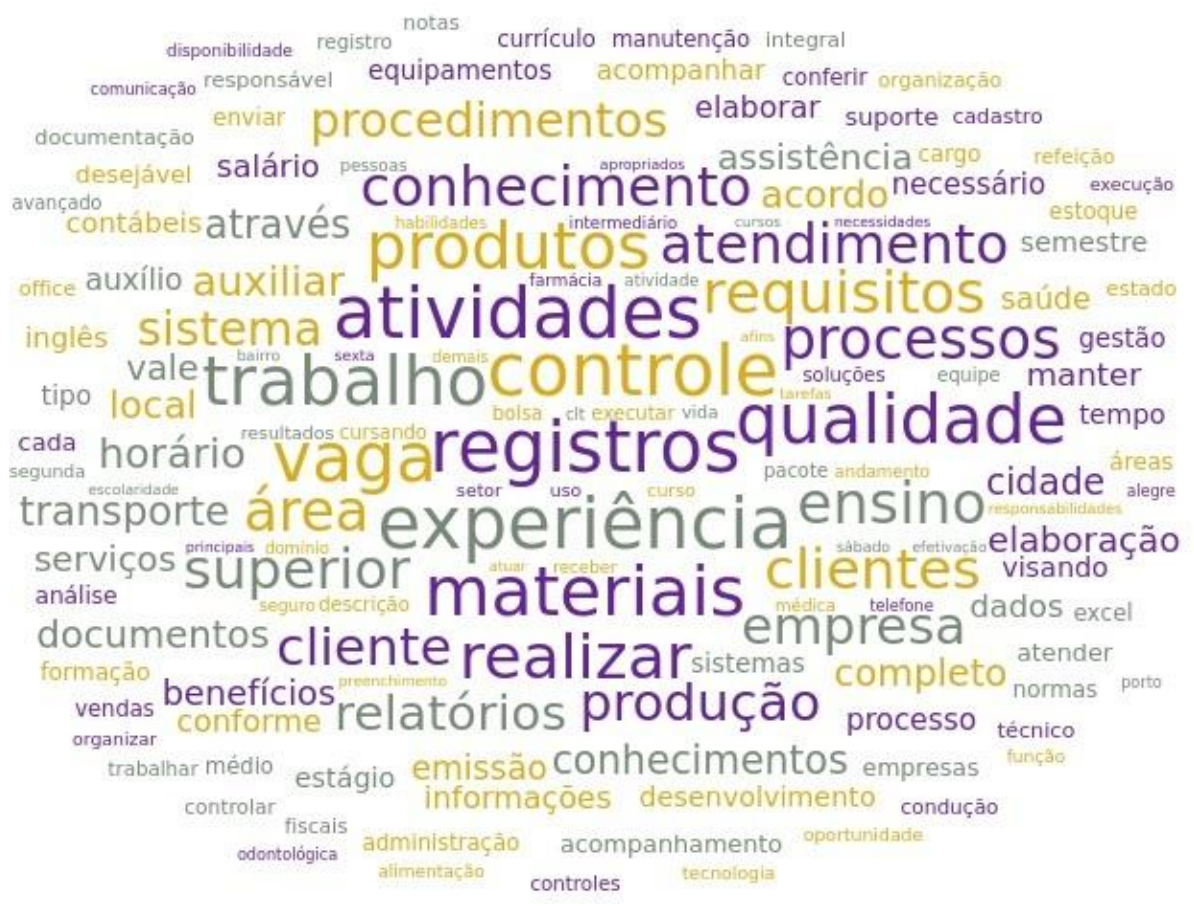

Fonte: Elaborado pelos autores (2019). 
O nicho chamado "Gerenciamento de Registros" é entendido como um conjunto de procedimentos coordenados para atender fins jurídico-administrativos que permitem o controle sobre os registros de uso constante e que em decorrência deste uso, se faz imperiosa uma verificação periódica para garantir que todas as etapas do processamento tenham sido cumpridas e estejam sendo mantidas.

Esse nicho corresponde a manutenção da sequência lógica da ordem, do controle, do armazenamento, do arquivamento dos conjuntos e itens documentais processados, e, que devem ser constantemente acondicionados, armazenados, dispostos sob critérios de (info)logística pela sua localização topográfica.

Vale salientar que essa localização pode coincidir com a estruturação classificatória ou lógica funcional do plano de classificação de documentos. Assim, uma vez registrados os documentos é preciso gerenciá-los e para tanto, deve-se também atribuir códigos de classificação para as peças e para as unidades simples. Um exemplo disto é codificar os diversos tipos de relatórios emitidos por um sistema ou autoridade para a tomada de decisão.

Ainda é possível tomar como exemplo um Arquivo institucional cuja custódia refira-se ás unidades documentais compostas, como processos ou dossiês, dentre outros. Seu acondicionamento pode receber a fixação com códigos de barras ou $Q R$ Code para cada unidade facilitando o desarquivamento, o empréstimo, o arquivamento e 0 gerenciamento.

Destaca-se que as empresas privadas, no Brasil, não estão obrigadas a realizar Gestão de Documentos no âmbito do Regimento Jurídico dos Arquivos (Lei número 8.159/1991) sendo livres para eliminar os documentos com os critérios particulares. Os definidores da política arquivística e informacional podem ser o profissional de arquivo ou os tomadores de decisão e os proprietários. Os sócios e os clientes podem pressionar as empresas privadas no sentido de adotarem a ISO 15489, porém não há marco legal obrigatório para as empresas privadas.

Deste modo, pode-se reconhecer que há nichos não mapeados que existem no setor público em empresas públicas, estados, municípios câmaras, tribunais e União possuem obrigação legal de cuidar dos arquivos enquanto bens do patrimônio público e não apenas, dos documentos de valor permanente (valor histórico, científico e cultural), mas também dos arquivos de valor corrente (valor informativo, contábil e probatório).

Isso ocorre porque a publicação de vagas no setor público obedece aos editais públicos e a uma regulação própria, ao passo que as empresas privadas se fazem representar com mais força nas plataformas digitais estudadas. Por isso, apesar de pouco representado nas plataformas, o setor público possui demanda por "Gestão Documental "e "Administração de Arquivos". Há ainda muitos Arquivos Públicos a serem criados e implantados, vide os 11.140 arquivos públicos de municípios dos dois poderes (executivo e legislativo) que deveriam existir e funcionar. É possível somar a esta demanda dos municípios, a necessidade de arquivos em todos os órgãos dos executivos, dos legislativos e dos judiciários federais, todas as repartições dos 26 estados federados em seus três poderes. Porém, de todo este universo constam apenas menos do 100 com uma visibilidade estável na web (MARIZ, 2012).

Há nichos a serem mapeados nos três poderes públicos, conforme o Regimento Jurídico dos Arquivos (Lei n. 8159/1991). Nota-se que ainda há um percurso de maturidade institucional para que o país conte com um Sistema Nacional de Arquivos consolidado e com capilaridade, a fim de que possa articular-se com os Sistemas Estaduais e os Municipais de Arquivos facilitando, deste jeito, a transparência, o 
combate à corrupção, a qualidade dos serviços públicos e a organização das estruturas administrativas brasileiras. Desta forma o mercado de trabalho ao profissional de arquivo parece se constituir como uma, dentre outras demandas reprimidas do país, como a demanda por infraestrutura.

A força de trabalho do profissional de arquivo, neste caso o arquivista, acha-se mobilizada para o rol de outras carreiras de Estado, sendo a sua estabilidade estratégica, para que não fique à mercê de oscilações de governos ou interesses corruptos. E além disto, para que possa com autonomia proteger as provas geradas pela administração pública. Em suma, trata-se de uma posição para segurança jurídica do Estado.

Tais condições são relevantes, porque uma vez esgarçados os contratos sociais (CASTELLS, 1999) também no mundo do trabalho, parece haver preferência do profissional recém-formados ou em busca de realocação, em localizar neste espaço digital o seu lugar de representação já fixado no marco legal no qual o termo "arquivista" vigora (BRASIL, 1978). Vale apontar que as atribuições para o profissional de grau superior são atuais, vide que a Lei 6.546/1978 prevê o processo informativo como objeto de trabalho deste profissional desde o seu planejamento, encaminhamento e acompanhamento (BRASIL, 1978).

Apesar do termo "arquivista" corresponder ao que regula a legislação, no que se diz respeito ao conjunto de termos mapeados ao decorrer do estudo (por isso usa-se no singular o termo "o profissional de arquivo"), correspondem às variações para as vagas ocupadas e ofertadas nas três plataformas pesquisadas, contendo os seguintes termos: "arquivista", "arquivista-consultor", "arquivologista", "arquivólogo", "arquiteto de informação", "analista jurídico", "analista de documentação", "assessor administrativo", "assistente administrativo", "analista de informação", "analista de gestão e segurança da informação", "assistente de arquivo", "document controller", "controlador de documentos", "documentalista”, "diretor de arquivo", "gestor de informação", "supervisor de documentação", "supervisor de documentação técnica", "técnico em documentação" e "supervisor de arquivo".

Estes novos podem ser o reflexo dos novos usos dos objetos e instrumentos do profissional de arquivo, tais como os documentos de arquivo em suporte eletrônico e a informação arquivística digital. Neste viés, é possível afirmar que as variâncias de termos estão no bojo da inovação desejável ao capitalismo, já que o rendimento será maior quanto mais significados são extraídos a partir do novo (DANTAS, 2006).

\section{CONSIDERAÇÕES FINAIS}

Conclui-se que apesar de legalmente correto, o termo "arquivista" não é o único que representa a demanda laboral do mercado privado, e que há 21 designações semânticas distintas em uso para empregar este profissional no mercado. Constatouse, ainda, que as representações digitais semânticas em tais plataformas são o reflexo dos nichos de mercado de trabalho, sendo tal representação diretamente proporcional às demandas dos empregadores sendo as variáveis para as vagas abertas ou preenchidas submetidas aos entendimentos dos tomadores de decisão.

Considera-se que dentre as designações encontradas na atualidade, a pesquisa, de caráter original, descobriu a adoção de novos termos em relação ao que já havia sido conhecido em Souza (2011), para designar as ofertas de trabalho ao profissional de arquivo, incluindo document controller (dentre outros termos que constam nos 
resultados), notadamente aplicado pelas empresas privadas que requerem serviços arquivísticos e de informação digital por plataformas digitais.

Assim, também pode constatar-se que as plataformas digitais são novos produtos de encaminhamento mediato e também instrumentos de controle associados aos usos dos computadores, sendo um dos usos a mediação digital de vagas de trabalho na web. Adicionalmente, foi possível concluir que os nichos de mercado do profissional de arquivos representados nestas plataformas, refletem a fragmentação das forças produtivas e têm acompanhado os interesses dos agentes do modelo infoprodutivo no qual a informação é produzida, processada, vendida, comprada e patrocinada. Estes nichos de mercado de trabalho da iniciativa privada representados nas plataformas digitais selecionadas são os seguintes: Documentação Técnica, Sistemas de Informação, Processamento Arquivístico e Gerenciamento de Registros.

Nestes quatro nichos da iniciativa privada, nota-se a necessidade de interação com as tecnologias da informação (notadamente a tecnologia digital), de modo que há novos desafios aos quais o profissional de arquivo podem contribuir, sobretudo no universo informático, por exemplo, em relação à segurança dos documentos digitais e/ou digitalizados, à classificação quanto ao acesso à informação registrada, à preservação a longo prazo (long-term) para fins probatórios, e, por fim, à preservação de registros transacionais e de suas qualidades ou propriedades arquivísticas (archival proprieties).

Artigo recebido em 03/02/2020 e aprovado em 24/04/2020.

\section{REFERÊNCIAS}

ASSOCIAÇÃO BRASILEIRA DE NORMAS TÉCNICAS-ABNT. NBR ISO 15489-Informação e documentação - Gestão de documentos de arquivo: Parte 1: Conceitos e princípios. Rio de Janeiro: ABNT, 2018.

BRASIL. Lei número 8.159 , de 8 de janeiro de 1991. Decretada pelo Congresso Nacional e sancionada pela Presidência da República. Dispõe sobre a política nacional de arquivos públicos e privados e dá outras providências.

. Lei número 6.546, de 4 de Julho de 1978. Decretada pelo Congresso Nacional e sancionada pela Presidência da República. Dispõe sobre a regulamentação das profissões de Arquivista e de Técnico de Arquivo, e dá outras providências.

BUCKLAND, Michael. Information and Society. MIT Press Essential Knowledge Series. Massachusetts Institute of Technology. Cambridge, 2017.

CACALY, Serge; Le COADIC, Yves-François. Fifty years of scientific and technical information policy in France (1955-2005). Journal of Information Science, SAGE Publications, 2007.

CASILLI, Antonio. En Attendant les Robots: enquête sur le travail du clic. Paris: Seuil, 2019.

CASTELLS, Manuel. A sociedade em rede. Volume I. 2a ed. São Paulo: Paz e Terra, 1999.

CHIAVENATO, Idalberto. Administração: Teoria, processo e prática. McGraw-Hill. São Paulo. 1987.

COOK, Michael. The management of information from archives. Brookfield, U.S.A. : Gower, 1986. 
DANTAS, Marcos. Trabalho material sígnico e mais-valia 2.0 nas condições do capitalinformação. In: SIERRA CABALLERO (coord.), Francisco. Capitalismo Cognitivo y Economía Social del Conocimiento. La lucha por el Código. Ediciones CESPAL, Quito: 2016.

DANTAS, Marcos. Informação como trabalho e como valor. Revista da Sociedade Brasileira de Economia Política, $\mathrm{n}^{\circ}$ 19, Rio de Janeiro, 2006, p. 44-72

DESCHAMPS, Jacqueline. Mediation. A Concept for Information and Communication Sciences. Concepts to Conceive 21st Century Society Set. Vol. 1. ISTE. 2019.

DURANTI, Luciana. Looking for a new generation of archivists throught a very cloudy horizon. In: SERVAIS, Paul, MIRGUET, Françoise. (ed). Archivistes de 2030: Réflexions prospectives. 2015, p.47-60.

FUCHS, Christian; SANDOVAL, Marisol. Digital workers of the world unite! A framework for critically theorizing and analysing digital labour. TripleC: Communication, Capitalism \& Critique: Journal for a Global Sustainable Information Society. v. 12, n. 2, 2014.

GIBBONS, Leisa. Exploring Social Complexity. In: Gilliland, Anne; McKemish, Sue; Lau, Andrew (ed.). Research in the Archival Multiverse. Monash University Publishing, Clayton, 2017.

LEMOS, André. Epistemologia da comunicação, neomaterialismo e cultura digital. Galáxia. n.43. São Paulo Jan./Apr. 2020.

HERSCOVICI, Alain. Economia da cultura e da comunicação. Vitória: Fundação Ceciliano Abel de Almeida/UFES, 1995.

KEMBER, Sarah; ZYLINSKA, Joanna. Life After New Media. Mediation as a Vital Process. MIT Press, Cambridge, Massachusetts and London. 2012.

MARIZ, Anna Carla Almeida. A informação na internet: arquivos públicos brasileiros. Editora da FGV, 2012.

MEAD, Jay. Measuring the value added by technical documentation: A review of research and practice. Technical Communication; Washington Vol. 45, Ed. 3, 1998, p. 353-379.

PAES, Marilena Leite. Arquivo: teoria e prática. 2 ed. revista e ampliada. Rio de Janeiro: Editora da FGV, 1997.

SANDRONI, Paulo (org). Novo Dicionário de Economia. 3 ed. Editora Best Seller. 1994.

SOUZA, Kátia Isabelli Melo de. Arquivista, visibilidade profissional: formação, associativismo e mercado de trabalho. Brasília: Starprint, 2011.

VAN DOORN, Niels. Platform Labor: On the Gendered and Racialized Exploitation of Low-Income ServiceWork in the 'On-Demand' Economy. Information, Communication \& Society, 20(6), 898-914. 2017.

YAKEL, Elisabeth. Archival representation. Archival Science. v3, Issue n.1, 2003, p.1-25. 